\title{
$\mathrm{Ti}-39 \mathrm{Nb}-6 \mathrm{Zr}$ 합금의 시효처리를 통한 미세조직 및 기계적 특성 제어
}

\author{
권현준 $^{1,3} \cdot$ 임가람 $^{1} \cdot$ 이용태 ${ }^{1} \cdot$ 이동근 ${ }^{2} \cdot$ 이준희 $^{3} \cdot$ 김승언 $^{1, *}$ \\ ${ }^{1}$ 한국기계연구원 부설 재료연구소 금속재료연구본부 \\ ${ }^{2}$ 순천대학교 신소재공학부 \\ ${ }^{3}$ 동아대학교 신소재공학과
}

\section{Effect of Aging Time and Temperature on Microstructure and Mechanical Properties of Ti-39Nb-6Zr Alloy}

\author{
Hyun Jun Kwon ${ }^{1,3}$, Ka Ram Lim ${ }^{1}$, Yong Tae Lee ${ }^{1}$, Dong Geun Lee ${ }^{2}$, \\ Jun Hee Lee ${ }^{3}$, and Seung Eon Kim ${ }^{1, *}$ \\ ${ }^{I}$ Metallic Materials Division, Korea Institute of Materials Science, Changwon 51508, Republic of Korea \\ ${ }^{2}$ Department of Materials Science and Engineering, Sunchon National University, Sunchon 57922, Republic of Korea \\ ${ }^{3}$ Department of Materials Science and Engineering, Dong-A University, Busan 49315, Republic of Korea
}

\begin{abstract}
The aim of this study is to optimize the microstructure and mechanical properties of $\mathrm{Ti}-39 \mathrm{Nb}-6 \mathrm{Zr}$ (TNZ40) for bio-implant applications. TNZ40 was designed to have a low elastic modulus ( 40 GPa) and good biocompatibility. However, the alloy shows relatively low strength compared to other titanium alloys for bio-implant. In the present study, we tried to obtain the proper combination of elastic modulus and strength by tailoring the direct aging conditions after severe plastic deformation. The mechanical properties are closely linked to characteristics including the distribution and volume fraction of precipitates.
\end{abstract}

(Received November 6, 2015; Accepted May 19, 2016)

Keywords: implant, titanium alloy, low elastic modulus, direct aging, microstructure, mechanical properties

\section{1. 서 론}

타이타늄(Ti)합금은 일반적으로 높은 비강도와 내식성을 지니고 있어 항공우주, 조선해양분야 등에서 고부가가치 소 재로서 널리 사용되어 왔다 [1-6]. 또한 우수한 생체적합성으 로 인하여 Ni-Cr합금 및 $\mathrm{Co}-\mathrm{Cr}-\mathrm{Mo}$ 합금과 함께 체내 이식용 임플란트(implant) 소재로도 적용가능하다. 타이타늄은 1952 년 스웨덴의 Per-Ingvar Brånemark에 의해 타이타늄 표면이 골조직과 결합하는 골융합(osseointegration) 현상이 발표된 후 1965년에 최초로 치과용 임플란트에 적용되었으며, 1970 년대 중반부터 본격적인 상업화가 이루어졌다. 최근에는 순 수 타이타늄 및 그 합금이 충전물(inlay), 크라운(crown), 골 절고정재, 인공관절, 페이스메이커(pacemaker), 스텐트 (stent) 등 다양한 부품에 폭넓게 사용되고 있다 $[7,8]$. 순수 타

*Corresponding Author: Seung Eon Kim

[Tel: +82-55-280-3326, E-mail: sek24@kims.re.kr]

Copyright (c) The Korean Institute of Metals and Materials
이타늄을 제외한 타이타늄 상용 합금인 Ti-6Al-4V의 경우, $\mathrm{Al}$ 및 $\mathrm{V}$ 과 같은 합금원소의 생체 유해성이 보고되면서 이를 대체하기 위한 우수한 기계적 특성을 가지면서도 인체친화 적인 타이타늄합금 개발이 요구되고 있다 $[9,10]$. 강도가 높 은 합금일수록 임플란트 수명이 증가할 뿐 아니라 식립 부위 의 단면적을 줄일 수 있게 됨으로써 경량화 및 식립 가능 범 위가 증가되는 이점이 있다. 하지만 단순히 합금의 강도만을 고려할 경우 탄성계수 상승에 따른 응력차폐효과(stress shield effect)가 발생하게 된다. 이는 높은 탄성계수를 갖는 임플란트 소재가 그 주변에 가해지는 하중의 대부분을 흡수 하게 됨으로써, 이 부위의 뼈가 통상 부담해왔던 인장, 압축, 굽힘 모멘트(moment)를 오랫동안 받지않게되어 골소실이 유발되고 이로 인해 임플란트 주위에 골다공증(osteoporosis) 등의 문제점을 야기시키는 현상을 말한다 [11-16]. 이와 같이 높은 탄성계수를 갖는 소재를 임플란트에 적용할 경우, 골 소 실로 인해 임플란트 수명이 단축되는 결과를 초래한다 


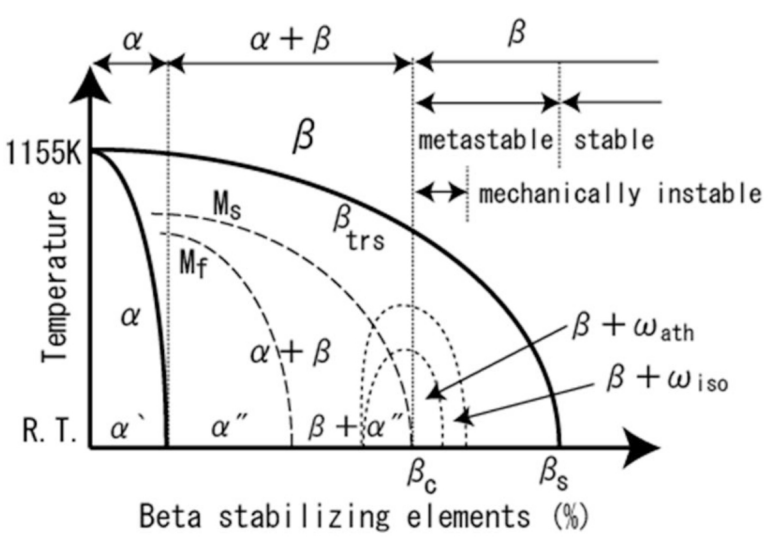

Fig. 1. Schematic partial phase diagram of beta titanium alloys[23]: $\beta_{\mathrm{c}}$ and $\beta_{\mathrm{s}}$ refer to the critical minimum amounts of $\beta$ stabilizer for metastable and stable $\beta$ alloys, respectively.

$[17,18]$. 따라서 임플란트용 합금의 경우에는 강도와 탄성계 수를 함께 고려할 필요가 있다. 현재까지 개발된 주요 합금으 로는 ASTM에 등재된 Ti-13Nb-13Zr(ASTM F1713), Ti-12Mo-6Zr-2Fe(ASTM F1813), Ti-15Mo(ASTM F2066) 등이 있고, 이외에도 Ti-35Nb-7Zr-5Ta, Ti-16Nb-13Ta-4Mo 등이 있다 [19]. 이들 합금은 베타(beta)안정화원소인 $\mathrm{Nb}, \mathrm{Zr}$, $\mathrm{Mo}, \mathrm{Fe}, \mathrm{Ta}$ 등이 다량 포함된 베타 타이타늄 합금으로서 순 수 타이타늄 $(105 \mathrm{GPa})$ 및 Ti-6Al-4V 합금 $(110 \mathrm{GPa})$ 에 비해 대체로 낮은 탄성계수 $(55 \mathrm{GPa} 91 \mathrm{GPa})$ 를 가지나, 인장강도 의 경우에는 순수 타이타늄 $(785 \mathrm{MPa})$ 및 Ti-6Al-4V 합금 (960 MPa-970 MPa)에 비해 대체로 비슷하거나 낮은 약 590 1100 MPa의 인장강도를 갖는 것으로 보고되었다 $[20,21]$. 전반적으로 살펴보면 낮은 탄성계수를 가질수록 인 장강도 또한 낮아지는 경향을 나타내었으며, 이로부터 두 가 지 특성이 서로 상충 관계(trade-off)에 있는 것을 알 수 있다. 본 연구에서는 기존 베타 타이타늄 합금들에 비해 높은 인장 강도와 낮은 탄성계수 조합을 갖는 타이타늄 합금 및 공정조 건을 도출하여 임플란트에 적합한 소재를 개발하는 것이 목 적이다. 이를 위해 본 연구에서는 베타 타이타늄 합금 중 가 장 낮은 탄성계수(베타 단일상일 경우 약 $40 \mathrm{GPa}$ )를 지니는 Ti-39Nb-6Zr 합금(TNZ40)을 선택한 후 [22], 탄성계수의 상 승을 최대한 억제하면서 인장강도(베타 단일상일 경우 약 $650 \mathrm{MPa}$ )를 향상시킬 수 있는 최적의 가공열처리 조건을 도 출하고자 하였다.
순도 $99.9 \% \mathrm{Ti}, 99.95 \% \mathrm{Nb}, 99.8 \% \mathrm{Zr}$ 원소재를 사용하여 진공 아크재용해(vacuum arc remelting) 방식으로 Ti-39Nb-6Zr (wt\%)의 조성을 갖는 직경 $120 \mathrm{~mm}$ 의 잉고트 (ingot)를 제조하였다. 이후 단조 및 압연공정을 거쳐 직경 $16.1 \mathrm{~mm}$ 의 봉재를 제조하였으며, 냉간 스웨이징(swaging)을 통해 최종적으로 직경 $8.5 \mathrm{~mm}$ 의 봉재를 준비하였다. 시편의 열처리를 위해 전기로(electric furnace, ELED F48020-80)를 이용하였으며 열처리 후 수냉하였다. 시효에 의한 TNZ40 합 금의 단면 조직 변화를 관찰하기 위해 미세연마한 시편을 $\mathrm{H}_{2} \mathrm{O}(100 \mathrm{ml})+\mathrm{HNO}_{3}(5 \mathrm{ml})+\mathrm{HF}(3 \mathrm{ml})$ 용액으로 에칭한 후 광 학현미경(optical microscope, OLYMPUS GX51)으로 관찰하 였으며, 상변화 관찰을 위해 $\mathrm{X}$-선 회절 분석(X-ray diffraction, RigakuD/MAX2500/PC)을 실시하였다. 미세 석 출물은 투과전자현미경(transmission electron microscope, FEI Tecnai $F 20 \mathrm{G}^{2}$ )을 이용하여 관찰하였으며, 기계적 특성 을 확인하기 위해 만능시험기(universal testing machine, INSTRON 4206)을 이용하여 인장시험을 실시하였다.

\section{3. 결과 및 고찰}

그림 1은 베타 타이타늄 합금의 부분상태도 [23]를 나타낸 다. Mo 당량에 따라 $\alpha, \alpha+\beta$, 준인정(metastable) $\beta$, 인정 (stable) $\beta$ 등으로 분류되며, 본 TNZ40 합금의 경우에는 아래 식 (1)과 (2)에 따라 계산해보면 약 $10 \%$ 의 Mo 당량을 가지므 로 준안정 베타 합금(metastable $\beta$ alloy) 영역(Mo 당량 $10 \sim 25 \%$ 범위)에 속한다.

$$
\begin{aligned}
{[\mathrm{Mo}]_{\mathrm{eq}}=} & {[\mathrm{Mo}]+0.2[\mathrm{Ta}]+0.28[\mathrm{Nb}]+0.44[\mathrm{~W}]+0.67[\mathrm{~V}]+1.6[\mathrm{Cr}] } \\
& +1.25[\mathrm{Ni}]+1.7[\mathrm{Mn}]+1.7[\mathrm{Co}]+2.9[\mathrm{Fe}]-1.0[\mathrm{Al}]
\end{aligned}
$$

$[\mathrm{Al}] \mathrm{eq}=[\mathrm{Al}]+0.17[\mathrm{Zr}]+0.33[\mathrm{Sn}]+10[\mathrm{O}]+10[\mathrm{C}]+20[\mathrm{~N}]$

부분 상태도에서 볼 수 있는 바와 같이 준안정 베타 합금의 경우 $\beta \rightarrow \alpha^{\prime \prime}$ 와 같은 마르텐사이트(martensite) 변태는 나타나 지 않으며 시효를 통해 $\omega$ 상과 $\alpha$ 상이 생성될 수 있음을 예상 할 수 있다. 이 경우, 합금의 시효 처리 시 생성되는 $\omega$ 상 및 $\alpha$ 상의 입도, 분율 및 분포에 따라 인장강도와 탄성계수가 큰 폭으로 변화하게 된다. 따라서 일반적으로 시효처리 온도 및 시간을 조절함으로써 기계적 특성 제어가 가능하다 [26-29]. 

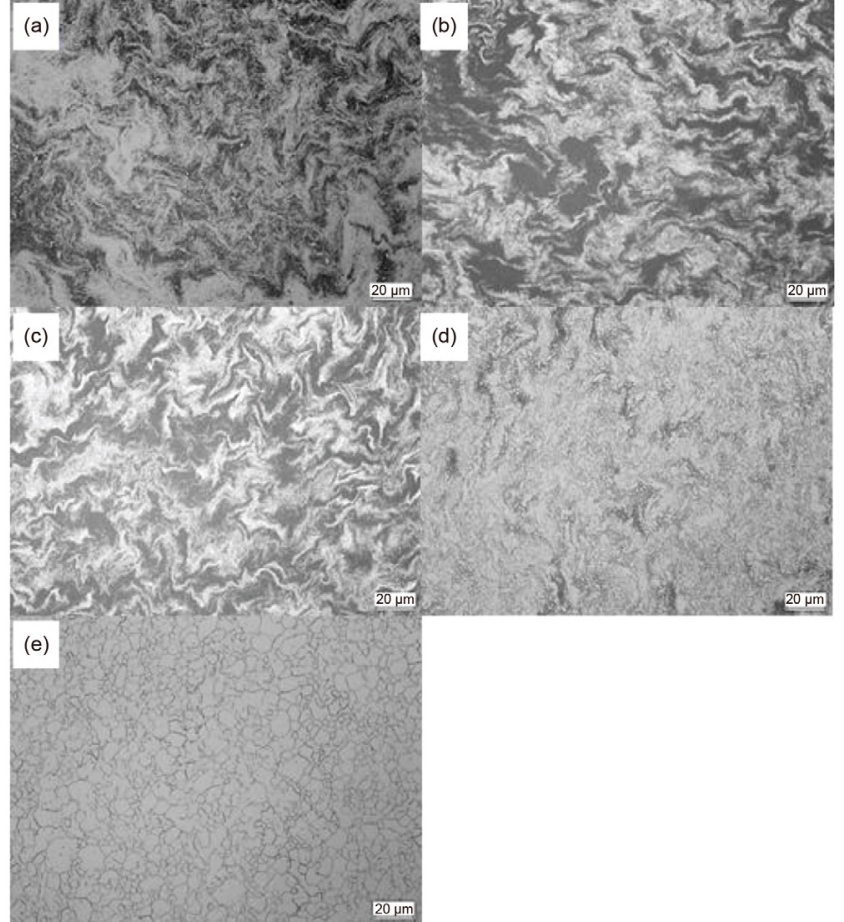

Fig. 2. Optical microscope images of TNZ40 samples: (a) as-swaged and isothermally held at (b) $450{ }^{\circ} \mathrm{C}$, (c) $500{ }^{\circ} \mathrm{C}$, (d) 550 ${ }^{\circ} \mathrm{C}$, and (e) $600{ }^{\circ} \mathrm{C}$ for 4 hours.

시효 처리 시, 생성되는 석출물을 적절히 제어하기 위해서는 오메가 용해도곡선 ( $\omega$-solvus) 및 베타 변태점( $\beta$-transus)을 정확히 아는 것이 중요하다. $\omega$-solvus 이하에서 시효 시에는 등온(isothermal) $\omega$ 상 $\left(\omega_{\text {iso }}\right)$ 이 석출되지만, $\omega$-solvus와 $\beta$ -transus 사이의 온도에서는 $\omega \rightarrow \alpha$ 변태를 통해 $\omega$ 상이 사라지 고 대신 $\alpha$ 상이 석출되기 때문이다. $\beta$-transus 이상의 온도에 서는 $\beta$ 기지 내에 모든 석출물들이 사라지게 된다.

먼저, $\beta$-transus를 알아보기 위해 냉간 스웨이징 가공된 $\mathrm{TNZ} 40$ 봉재를 $450,500,550,600{ }^{\circ} \mathrm{C}$ 에서 각각 4 시간씩 열처 리한 후 상변화를 관찰하였다. 그림 2에 각 온도에서 열처리 된 시편을 광학현미경으로 촬영한 사진을 나타내었다. 열처 리 온도가 높아질수록 냉간 가공에 의해 축적된 물결 패턴 (wavy pattern)이 약화되는 것을 볼 수 있으며 $600{ }^{\circ} \mathrm{C}$ 에서 열 처리한 경우에는 결정립계가 선명하게 나타났다. 각 온도별 상변화를 확인하기 위해 X-선 회절 분석을 실시하였으며 그 림 3은 각 시편의 X-선 회절 패턴을 보여준다. 그림 3(a)는 냉 간 스웨이징 가공 직후(as-swaged)의 X-선 회절 패턴을 나타 내고 있으며 이를 통해 as-swaged 상태에서는 시편 조직이 단 일 $\beta$ 상으로 이루어져 있음을 확인하였다. 반면, $450{ }^{\circ} \mathrm{C}$ (그림 $3(\mathrm{~b})), 500{ }^{\circ} \mathrm{C}($ 그림 $3(\mathrm{c})), 550{ }^{\circ} \mathrm{C}$ (그림 $\left.3(\mathrm{~d})\right)$ 에서 열처리한 경

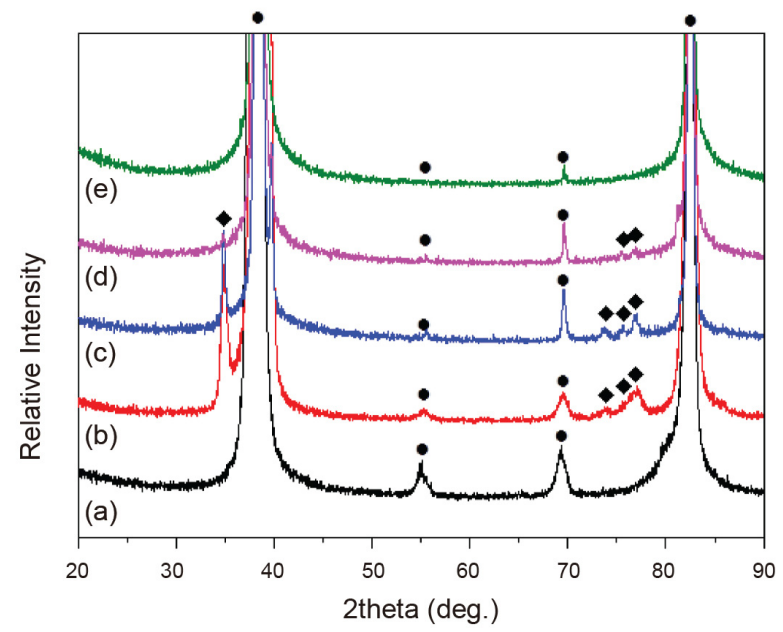

Fig. 3. X-ray diffraction patterns obtained from TNZ40 samples: (a) as-swaged and isothermally held at (b) 450, (c) 500, (d) 550, and (e) $600{ }^{\circ} \mathrm{C}$ for 4 hours $(\bullet: \beta$ and $\diamond: \alpha)$.

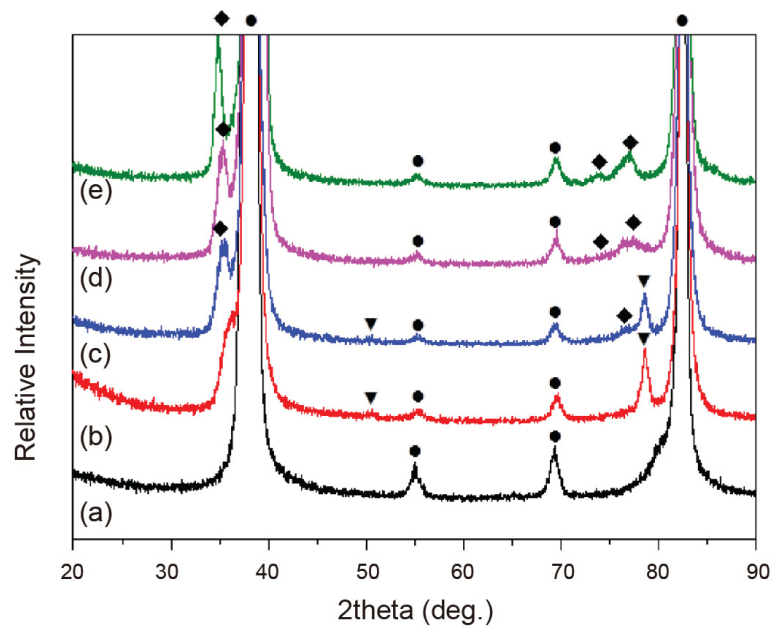

Fig. 4. X-ray diffraction patterns obtained from TNZ40 samples: (a) as-swaged and isothermally held at (b) 380, (c) 400, (d) 430, and (e) $450{ }^{\circ} \mathrm{C}$ for 4 hours $(\bullet: \beta, \diamond: \alpha$, and $\boldsymbol{\nabla}: \omega)$.

우에는 $\alpha$ 상이 일부 생성된 것을 확인할 수 있다. 하지만 600 ${ }^{\circ} \mathrm{C}$ 에서 열처리한 경우에는 $\alpha$ 피크(peak)가 나타나지 않았다. 이러한 결과로부터 $\beta$-transus가 $550 \sim 600{ }^{\circ} \mathrm{C}$ 사이에서 형성되 는 것을 알 수 있으며, 이는 문헌과도 잘 일치한다 [30-32]. 다 음으로 $\omega$-solvus를 알아보기 위해 as-swaged 봉재를 380 , $400,430,450{ }^{\circ} \mathrm{C}$ 에서 각각 4 시간씩 열처리한 후 $\mathrm{X}$-선 회절 패 턴을 통해 상변화를 관찰하였다(그림 4). TNZ40 합금과 조성 이 유사한 Ti-35Nb-7Zr-5Ta(TNZT) 합금의 경우 $\omega$-solvus가 약 $400{ }^{\circ} \mathrm{C}$ 근처에서 형성되는 것으로 알려져있으며 [33], 본 합금의 경우에도 이와 비슷한 온도에서 $\omega$-solvus가 형성되는 
Table 1. Comparison of the tensile mechanical properties of as-swaged TNZ40 sample and the samples directly aged at 380 , 400 , and $430{ }^{\circ} \mathrm{C}$ for 4 hours: yield stress $\sigma_{\mathrm{y}}$, ultimate tensile strength $\sigma_{\max }$, and Young's modulus $E$.

\begin{tabular}{c|ccc}
\hline $\begin{array}{c}\text { Isothermal aging } \\
\text { condition }\end{array}$ & $\sigma_{\mathrm{y}}(\mathrm{MPa})$ & $\sigma_{\max }(\mathrm{MPa})$ & $\mathrm{E}(\mathrm{GPa})$ \\
\hline As-swaged & $880 \pm 2$ & $890 \pm 1$ & $68 \pm 2$ \\
\hline $380{ }^{\circ} \mathrm{C}$ & $1220 \pm 8$ & $1297 \pm 1$ & $89 \pm 3$ \\
\hline $400{ }^{\circ} \mathrm{C}$ & $1125 \pm 9$ & $1205 \pm 12$ & $77 \pm 3$ \\
\hline $430{ }^{\circ} \mathrm{C}$ & $1003 \pm 16$ & $1100 \pm 4$ & $68 \pm 3$ \\
\hline
\end{tabular}



Fig. 5. Tensile engineering stress-strain curves of TNZ40 samples: (a) as swaged and directly aged at (b) 380, (c) 400, and (d) $430{ }^{\circ} \mathrm{C}$ for 4 hours.

것으로 예상하였다. As-swaged 상태에서는 시편 조직이 단일 $\beta$ 상으로 존재하다가 $380{ }^{\circ} \mathrm{C}$ 에서 열처리 시에는 $\omega$ 상이 생성 되다가 $400{ }^{\circ} \mathrm{C}$ 에서 열처리 시에는 $\omega$ 상과 $\alpha$ 상이 모두 생성된 것을 알 수 있다. $430{ }^{\circ} \mathrm{C}$ 이상의 온도에서 열처리 한 경우에는 $\omega$ 피크가 사라지고 $\alpha$ 피크가 더욱 발달한 것으로 나타났다. 이러한 결과로부터 TNZ40 합금의 $\omega$-solvus는 $400{ }^{\circ} \mathrm{C}$ 와 430 ${ }^{\circ} \mathrm{C}$ 사이에서 형성되는 것을 알 수 있다.

시효 시 석출 거동에 따른 기계적 특성 변화를 살펴보기 위 해 as-swaged TNZ40 합금 봉재를 각각 $380{ }^{\circ} \mathrm{C}, 400{ }^{\circ} \mathrm{C}, 430$ ${ }^{\circ} \mathrm{C}$ 에서 4시간씩 열처리 후 인장시험 결과를 그림 5 와 표 1 에 나타내었다. 그림 5는 각 시편의 응력-변형률 곡선을 나타내 며, 이로부터 얻어진 인장특성(항복강도, 인장강도, 탄성계 수)을 표 1 에 정리하였다. 표 1에서 볼 수 있는 바와 같이 as-swaged 상태에서의 항복강도와 인장강도는 각각 약 880 $\mathrm{MPa}$ 과 $890 \mathrm{MPa}$ 로 단일 베타상으로 존재할 때보다 비교적 높 은 값을 나타내었지만, 탄성계수 또한 약 $68 \mathrm{GPa}$ 로 단일 베타 상일 경우에 비해 약 $25 \mathrm{GPa}$ 정도 상승하였다. 그 원인을 알 아보기 위해 투과전자현미경을 이용하여 미세조직을 관찰한
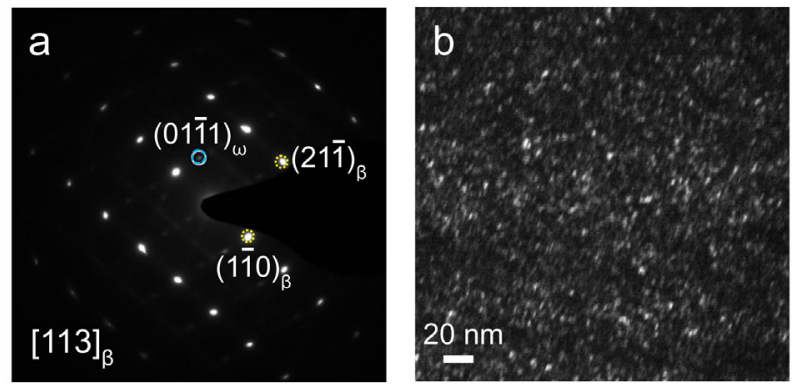

Fig. 6. (a) A selected area electron diffraction pattern of [113] zone axis obtained from as-swaged TNZ40; (b) a dark field transmission electron microscope (TEM) image taken from the $(01 \overline{1} 1)_{\omega}$ reflection, showing fine $\omega$ precipitates in the $\beta$ matrix.

결과, X-선으로는 검출이 어려운 미세 석출물들이 생성되어 있음을 확인하였다. 그림 6(a)는 as-swaged 시편의 [113] 결 정띠축(zone axis)에서 촬영한 제한시야 전자회절 패턴 (selected area electron diffraction pattern)을 나타낸 것인데, $(21 \overline{1})_{\beta}$ 회절점의 $1 / 3$ 과 $2 / 3$ 지점에 $\omega$ 피크가 관찰되는 것을 알 수 있다. 그림 6(b)는 $(01 \overline{1} 1)_{\omega}$ 회절점의 암시야상(dark field image)을 나타낸 것인데 이를 통해 수 $\mathrm{nm}$ 크기의 미세 $\omega$ 석출 물들이 균일하게 분포하는 것을 확인하였다. 따라서 냉간 스 웨이징 가공 시 이러한 미세 $\omega$ 석출물들이 다량 생성됨으로 써 베타 단일상으로 존재할 때보다 탄성계수, 항복강도, 인장 강도가 모두 증가된 것으로 볼 수 있다. 시효 이후의 기계적 특성을 살펴보면 시효 온도에 따라 큰 차이가 나는 것을 알 수 있는데, 이는 석출 거동 변화에 기인한다. $380{ }^{\circ} \mathrm{C}$ 에서 시효시 킨 시편의 경우 항복강도(약 $1220 \mathrm{MPa}$ ), 인장강도(약 1297 $\mathrm{MPa})$, 탄성계수(약 $69 \mathrm{GPa})$ 모두 최대치를 나타내었다. 앞서 언급한 바와 같이, 이 경우 $\omega$ 상의 석출이 기계적 특성 변화에 크게 기여한 것을 알 수 있다. $400{ }^{\circ} \mathrm{C}$ 에서 시효시킨 시편의 경 우 $380{ }^{\circ} \mathrm{C}$ 에 비해 항복강도, 인장강도, 탄성계수 등이 모두 약 간씩 감소하는 것으로 나타났다. 이 경우는 $\omega$ 석출물 중 일부 가 $\alpha$ 상으로 변태되기 시작하면서 $\omega$ 석출물의 분율이 감소하 게 되기 때문인 것으로 여겨진다. 마지막으로 $430{ }^{\circ} \mathrm{C}$ 에서 시 효시킨 시편의 경우에는 세 가지 시효 조건 중에서는 가장 낮 은 기계적 물성을 나타내었다. 이는 $\omega$-solvus보다 높은 온도 에서 시효시킴으로써 $\omega$ 석출물이 대부분 사라지고 $\beta$ 기지 내 에 $\alpha$ 석출물만이 존재하기 때문인 것으로 여겨진다. 각 온도 에 따른 석출물의 종류, 분율, 분포 등의 변화를 보다 면밀히 살펴보기 위해 투과전자현미경을 이용하여 미세조직을 관찰 하였다.

그림 7(a)는 $400{ }^{\circ} \mathrm{C}$ 에서 4 시간 시효시킨 시편의 $[113]_{\beta}$ 결 

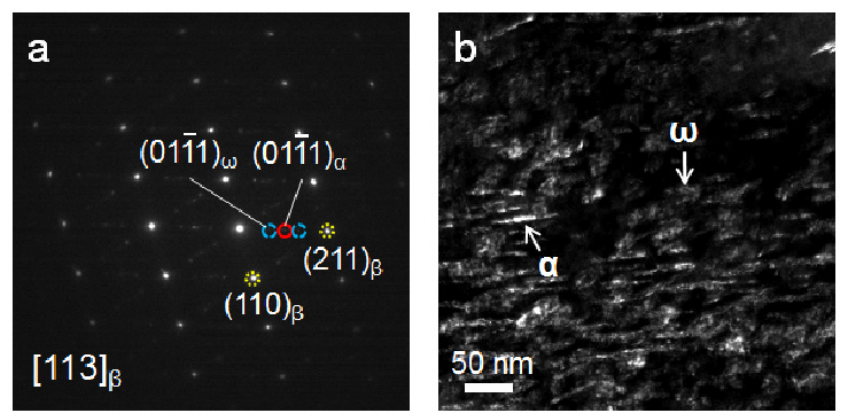

Fig. 7. (a) A selected area electron diffraction pattern of $[113]_{\beta}$ zone axis obtained from the TNZ40 sample isothermally held at $400{ }^{\circ} \mathrm{C}$ for 4 hours. (b) A dark field TEM image taken from the $(01 \overline{1} 1)_{\omega}$ and $(01 \overline{1} 1)_{\alpha}$ reflections, showing ellipsoidal $\omega$ particles and fine $\alpha$ laths in the $\beta$ matrix.

정띠축에서 촬영한 제한시야 전자회절 패턴을 나타낸 것이 다. 이 경우 $(21 \overline{1})_{\beta}$ 회절점의 $1 / 3$ 과 $2 / 3$ 지점에서 $\omega$ 피크가, $1 / 2$ 지점에서는 $\alpha$ 피크가 관찰되었으며 이는 $\mathrm{X}$-선 회절 분석 결과(그림 4(c))와도 일치한다. 그림 7(b)는 $(01 \overline{1} 1)_{\omega}$ 와 $(01 \overline{1}$ $1)_{\alpha}$ 회절점을 동시에 포함하는 암시야상을 나타낸 것인데, 수 십 $\mathrm{nm}$ 크기의 라스(lath) 타입의 $\alpha$ 상과 타원형(ellipsoidal) 타 입의 $\omega$ 상이 비교적 균일하게 분포하는 것으로 나타났다. 특 히 $\alpha$ 상의 경우 $\omega$ 상과 인접하여 생성된 것을 관찰할 수 있는 데, 이는 $\omega$ 상이 $\alpha$ 상의 불균일핵생성 사이트(site)로 작용하기 때문이다 [34]. 이로부터 시효온도 상승에 따른 석출상의 종 류 및 분율 변화는 $\omega \rightarrow \alpha$ 변태에 기인하는 것을 확인할 수 있 었다. 지금까지의 결과를 종합해보면, 강도 및 탄성계수는 주 로 $\omega$ 상 및 $\alpha$ 상의 분율에 비례한다는 것을 알 수 있으며, 특히 $\omega$ 상의 존재가 기계적 특성에 큰 영향을 미친다는 것을 알 수 있다. 또 한가지 흥미로운 사실은 시효온도가 $430{ }^{\circ} \mathrm{C}$ 인 경우 에는 탄성계수가 as-swaged 상태와 비슷한 수준(약 $68 \mathrm{MPa}$ ) 으로 회복되지만 항복강도(약 $1003 \mathrm{MPa}$ ) 및 인장강도(1100 $\mathrm{MPa}$ )는 as-swaged 상태보다 약 100 200 MPa 높다는 점이 다. 시효 시 생성된 $\alpha$ 상의 분율이 as-swaged 상태의 $\omega$ 상 분율 에 비해 높음에도 불구하고 탄성계수 증가폭이 비슷하다는 것은 $\alpha$ 상이 $\omega$ 상에 비해 탄성계수에 미치는 영향이 작기 때문 인 것으로 여겨진다.

\section{4. 결 론}

본 연구에서는 냉간 스웨이징 가공된 TNZ40 합금의 시효 처리를 통해 석출상 생성 및 그에 따른 인장특성 변화를 살펴 보았다. TNZ40 합금의 경우 Mo 당량이 약 $10 \%$ 인 준안정 베
타합금으로 분류되며, $\beta$-transus는 $550 \sim 600{ }^{\circ} \mathrm{C}$ 사이에서, $\omega$ -solvus는 400 430 $\quad{ }^{\circ} \mathrm{C}$ 사이에서 형성됨을 확인하였다. as-swaged TNZ40 봉재의 경우 $\beta$ 기지 내에 수 $\mathrm{nm}$ 크기의 $\omega$ 석출물들이 다량 생성되어 있었으며, $380{ }^{\circ} \mathrm{C}$ 시효 시 수십 $\mathrm{nm}$ 크기의 $\omega$ 상이 석출되는 것을 확인하였다. 하지만 $400{ }^{\circ} \mathrm{C}$ 시효 시 $\omega$ 상에서 $\alpha$ 상으로의 변태가 일부 발생하게 되며, 430 ${ }^{\circ} \mathrm{C}$ 이상의 온도에서는 $\omega$ 상이 거의 소멸되고 $\alpha$ 상의 분율이 증 가하는 것을 확인하였다. 인장시험 결과, $380{ }^{\circ} \mathrm{C}, 4$ 시간 시효 시 약 $1300 \mathrm{MPa}$ 급의 가장 높은 인장강도를 나타내었으며 탄성계수 또한 약 $89 \mathrm{GPa}$ 로 비교적 높은 값을 보여주었다. 반면, $430{ }^{\circ} \mathrm{C}, 4$ 시간 시효 시에는 $\omega$ 상 대신 $\alpha$ 상이 석출되므로 탄성계수 값은 as-swaged 상태와 동등 수준인 약 $68 \mathrm{GPa}$ 을 나타내며 인장강도는 as-swaged 상태보다 약 $200 \mathrm{MPa}$ 증가 되는 것을 확인하였다. $400{ }^{\circ} \mathrm{C}, 4$ 시간 시효 시에는 $\omega$ 상과 $\alpha$ 상 혼재하므로 $380{ }^{\circ} \mathrm{C}$ 와 $430{ }^{\circ} \mathrm{C}$ 사이의 기계적 물성을 나타내었 다. $\omega$ 상과 $\alpha$ 상 모두 강도와 탄성계수 증가에 영향을 주는 것 으로 보이나, 시효 시 강도 및 탄성계수의 급격한 증가는 주 로 $\omega$ 상의 분율에 큰 영향을 받는 것으로 사료된다. 따라서 높 은 인장강도를 얻는 것이 중요할 경우에는 시효온도를 $\omega$ -solvus 이하에서 설정하여 $\omega$ 상의 분율을 증가시키고, 인장 강도보다는 낮은 탄성계수를 얻는 것이 목적이라면 시효온 도를 $\omega$-solvus 이상에서 설정하여 $\alpha$ 상의 분율을 증가시키는 것이 바람직하다. $\omega$ 석출물의 분율을 적정수준 유지하면서 미세 $\alpha$ 석출물들을 다량 생성시키는 것이 높은 인장강도와 낮은 탄성계수 조합을 얻는 최적의 방법이라고 하겠다.

\section{감사의 글}

본 연구는 정부(산업통상자원부)의 재원으로 지식경제부 사업(No. 10037915) 지원을 받아 수행되었으며, 이에 감사드 립니다.

\section{REFERENCES}

1. D. Iijima, T. Yoneyama, H. Doi, H. Hamanaka and N. Kurosaki, Biomaterials 24, 1519 (2003).

2. F. H. Froes, JOM-J. Min. Met. Mat. S. 50, 15 (1998).

3. C. M. Agrawal, JOM-J. Min. Met. Mat. S. 50, 31 (1998).

4. Y. T. Lee and Y. T. Hyun, J. Kor. Inst. Met. \& Mater. 30, 862 (1992).

5. K. Hajizadeh and B. Eghbali, Met. Mater. Int. 20, 343 (2014). 
6. T. K. Lee, M. Nakai, M. Niinomi, C. H. Park and C. S. Lee, Met. Mater. Int. 21, 202 (2015).

7. B. K. Brånemark, Osseointegration, www.branemark.se. (2010).

8. J. D. Shim and H. K. Seok, Biomater. Res. 15, 176 (2011).

9. Y. Okazaki, S. Rao, S. Asao, T. Tateishi, S. Katuda and Y. Furuki, J. Jpn. I. Met. 60, 890 (1996).

10. E. H. Greener, J. B. Moser, J. Opp, K. Szurgot and B. C. Marker, Dent. Mater. 5, 45(1986).

11. D. R. Sumner and J. O. Galante, Clin. Orthop. Relat. R. 274, 202 (1992).

12. E. J. Chel, M. Spector and W. C. Haye, Clin. Orthop. Relat. R. 10, 405 (1992).

13. P. J. Prendergast and D. Taylor, J. Biomed. Eng. 12, 379 (1990).

14. B. V. Rietbergen, R. Huiskes, H. Weinans, D. R. Sumner, T. M. Turner and J. O. Galante, J. Biomech. 26, 369 (1993).

15. R. Huiskes, H. Weinans and B. V. Rietbergen, Clin. Orthop. Relat. R. 274, 124 (1992).

16. A. R. Dujovne, J. D. Bobyn, J. J. Krygier, J. E. Miller and C. E. Brooks J. Arthroplasty 8, 7 (1993).

17. T. P. Vail, R. R. Glisson, T. D. Koukoubis and F. Guilak, Biomechanics 31, 619 (1998).

18. T. H. Mallory, A. V. Lombardi, J. R. Leith, H. Fujita, J. F. Hartman, S. G Capps, C. A. Kefauver, J. B. Adams and G. Christian, J. Arthroplasty 16, 49 (2001).

19. M. Niionomi, Sci. Technol. Adv. Mat. 4, 445 (2003).

20. D. Kuroda, M. Niinomi, M. Morinaga, Y. Kato and T. Yashiro, Mater. Sci. Eng. A 243, 244 (1998).

21. M. Niionomi, Mater. Sci. Eng. A 243, 231 (1998).
22. Korea Patent 10-0971649-0000, "Beta-Based Titanium Alloy with Low Flastic Modulus" (2010).

23. P. Wilson, Recent Developments in the Study of Recrystallization: Chapter4 Texturing Tendency in $\beta$ -Type Ti-Alloys, InTech, Croatia (2013).

24. P. J. Bania, Proc. A Symposium on Beta Titanium Alloys (eds. D. Eylon, R. R. Boyer, and D. A. Koss), pp.3, Minerals, Metals \& Materials Society, Warrendale, Pa. (1993).

25. H. W. Rosenberg, The Science, Technology and Application of Titanium, pp.851, Pergamon Press, Oxford, UK (1970).

26. C. Leyens and M. Peters, Titanium and Titanium Alloys: Fundamentals and Applications, WILEY-VCH, Weinheim (2003).

27. R. R. Boyer, Mater. Sci. Eng. 213, 103 (1996).

28. S. Ankem and C. A. Greene, Mater. Sci. Eng. 263, 127 (1999).

29. G. Lutjering and J. C. Williams, Titanium, 2nd ed., pp.16, Springer-Verlag, Berlin, Germany (2007).

30. Phys. Met. Metallogr.(USSR), 23, 28 (1967).

31. T. Doi, H. Ishida and T. Umezawa, Study of $\mathrm{Nb}-\mathrm{Zr}-\mathrm{Ti}$ Phase Diagram (Studies of Hard Superconductor, II), Nippon Kinzoku Gakkaishi 30, 139 (1966).

32. K. C. Hari Kumar, P. Wollants and L. Delaey, J. Alloys Compd. 206, 121 (1994).

33. S. Nag, (Influence of Beta Instabilities of the Early Stages of Nucleation and Growth of Alpha in Beta Titanium Alloys), Ph.D. Thesis, The Ohio State University (2008).

34. A. Rabinkin, M. Talianker and O. Botstein, Acta Metall. Mater. 29, 691 (1981). 